\title{
Alveolar Haemorrhage in the Immunocompetent Host: A Scale for Early Diagnosis of an Immune Cause
}

\author{
Clément Picard $^{\mathrm{a}, \mathrm{d}}$ Jacques Cadranel ${ }^{\mathrm{a}}$ Raphaël Porcher ${ }^{\mathrm{c}}$ Hélène Prigent $^{\mathrm{a}}$ \\ Pierre Levy ${ }^{\mathrm{b}}$ Muriel Fartoukh ${ }^{\mathrm{a}} \quad$ Charles Mayaud $^{\mathrm{a}} \quad$ Antoine Parrot $^{\mathrm{a}}$ \\ a Service de Pneumologie et Réanimation and Centre de Compétence sur les Maladies Rares Pulmonaires and \\ ${ }^{b}$ Unité de Biostatistiques et Informatique Médicale, Hôpital Tenon, Assistance Publique - Hôpitaux de Paris, \\ and 'Département de Biostatistiques et d'Informatique Médicale, Hôpital Saint-Louis, Paris, and d Service de \\ Pneumologie, Hôpital Foch, Suresnes, France
}

\section{Key Words}

Alveolar haemorrhage • Diagnosis score • Vasculitis •

Autoimmune disease $\cdot$ Left ventricular failure

\begin{abstract}
Background: Diffuse alveolar haemorrhage (DAH) is a lifethreatening condition due to immune and non-immune causes. Early identification of an underlying immune disorder is essential in order to initiate appropriate treatment. $\mathbf{O b}$ jective: The purpose of this study was to identify early predictive factors of an immune cause of DAH. Methods: We conducted a retrospective study of 76 immunocompetent patients with DAH to identify early predictive factors of immune-related DAH using clinical, radiological and routine biological data available in the first $24 \mathrm{~h}$ after hospital admission. Results: Multivariate analysis identified 4 parameters which were independently associated with immune-related $\mathrm{DAH}$ : (1) onset of first respiratory symptoms $\geq 11$ days, (2) fatigue and/or weight loss during the month prior to presentation, (3) arthralgias or arthritis and (4) proteinuria $\geq 1 \mathrm{~g} / \mathrm{l}$. A simplified scale was constructed using these variables, with an area under the receiver operating characteristic curve of
\end{abstract}

0.913, for the diagnosis of immune-related DAH. Conclusions: A simple diagnostic scale can be used to identify an immune-related cause of DAH in immunocompetent patients and may help guide treatment decisions such as initiation of steroid therapy on the day of admission.

Copyright $\odot 2010$ S. Karger AG, Basel

\section{Introduction}

Diffuse alveolar haemorrhage (DAH) is a rare pulmonary condition that can be associated with a wide variety of immune and non-immune disorders [1-5]. It is a lifethreatening condition with a mortality rate of approximately $20 \%[6,7]$. Intensive care unit (ICU) admission is required in up to $50 \%$ of cases because of acute respiratory failure, which can complicate investigative procedures especially if mechanical ventilation is required. Prompt treatment adapted to the underlying cause is crucial, and for immune-related DAH the use of immunosuppressors could be life and function saving [8]. Unfortunately, the aetiological diagnosis is often difficult to establish. Identification of most immune causes is based on

\section{KARGER}

Fax +41613061234 E-Mail karger@karger.ch www.karger.com
(C) 2010 S. Karger AG, Base

$0025-7931 / 10 / 0804-0313 \$ 26.00 / 0$

Accessible online at:

www.karger.com/res
Antoine Parrot, MD

Service de Pneumologie et Réanimation, Hôpital Tenon

Assistance Publique - Hôpitaux de Paris

4 Rue de la Chine, FR-75020 Paris (France)

Tel. +33 15601 6574, Fax +33 15601 6649, E-Mail antoine.parrot@tnn.aphp.fr 
tests for immunological markers or organ (often renal) biopsy. However, these are rarely available within the first $24 \mathrm{~h}$ and diagnostic tests are sometimes difficult to perform in critically ill patients [9].

In this setting, we conducted a retrospective study of 76 non-immunocompromised patients presenting with symptomatic DAH to identify features associated with an immune cause based on routine clinical, radiological and laboratory data available within the first $24 \mathrm{~h}$ after admission. A clinical scale to facilitate early identification of an immune cause was subsequently established.

\section{Methods}

\section{Study Design and Population}

All patients included in this retrospective study were recruited in a single ICU and pulmonary unit of an 800-bed tertiary hospital in Paris between 1980 and 2002. Patients with a final diagnosis of symptomatic DAH were identified by searching the admission registry (1980-1995) and a computer database (1995-2002).

Symptomatic DAH was defined as the association of a compatible clinical and/or radiological presentation with macroscopically haemorrhagic bronchioloalveolar lavage (BAL) fluid and/or haemorrhagic and siderophagic alveolitis on BAL cytology, or transbronchial or surgical lung biopsy. Patients with haemoptysis of bronchial origin, chronic renal failure or human immunodeficiency virus infection were excluded, as were patients with haematological or solid malignancies receiving cytotoxic chemotherapy or radiotherapy for $\geq 2$ months, patients receiving immunosuppressant or glucocorticosteroid therapy for $\geq 2$ months or organ transplant recipients.

One hundred and twenty patients with a final diagnosis of symptomatic DAH were identified from the registry and the computer database. Seventy-six patients were included in the final analysis; the remaining 44 patients were subsequently excluded for the following reasons: insufficient data, especially for patients treated subsequently in other institutions $(n=10)$; haemorrhage of possible bronchial origin not excluded $(n=33)$, and diagnosis of immunodeficiency such as HIV infection or haematological malignancy during the same hospital stay $(n=1)$.

For each case, the underlying aetiology of the DAH was strictly reviewed. Diagnostic criteria for immune causes were adapted from the following references: microscopic polyangiitis [10], Wegener's granulomatosis [11, 12], Henoch-Schönlein purpura [13], anti-glomerular basement membrane antibody disease $[14,15]$, collagen vascular diseases [systemic lupus erythematosus (SLE) and mixed connective tissue disease] [16] and rheumatoid arthritis [17]. The underlying immune disease was previously undiagnosed in all cases. Patients were then separated into 2 groups: patients with DAH of immune cause (group 1) and patients with DAH of non-immune cause (group 2). Group 1 included 32 patients with DAH due to vasculitis [microscopic polyangiitis ( $\mathrm{n}=$ $10)$, Wegener's granulomatosis $(\mathrm{n}=10)$, Henoch-Schönlein purpura $(n=1)$ and unclassified vasculitis $(n=2)]$, collagen vascular disease [SLE $(n=4)$ and mixed connective tissue disease $(n=1)]$, rheumatoid arthritis ( $n=1)$ and antiglomerular basement mem- brane antibody disease $(n=3)$. Group 2 included 44 patients with DAH due to cardiac failure [left ventricular failure $(n=7)$ and mitral stenosis $(n=5)]$, clotting disorder $(n=8)$, barotraumatic stress capillary failure $(n=3)$, non-immune-mediated toxic- or drug-induced causes [cannabis $(\mathrm{n}=1)$, glue sniffing $(\mathrm{n}=1)$ and nitrosourea $(n=1)$ ], cancer [uterine sarcoma $(n=1)$ and nonsmall cell lung carcinoma $(\mathrm{n}=1)$ ], infection [anaerobic pneumonia $(\mathrm{n}=1)$, strongyloidiasis $(\mathrm{n}=1)$ and filariosis $(\mathrm{n}=1)$ ] and idiopathic DAH $(\mathrm{n}=13)$. Idiopathic DAH was only considered when DAH remained unexplained after exhaustive evaluation and long-term follow-up. Most patients in the idiopathic DAH subgroup had only 1 acute episode with no recurrence; consequently, invasive procedures (surgical biopsy) were not considered in most cases and only 4 of 13 patients had transbronchial biopsies. The rate of idiopathic cases remained stable during the study period.

Routine clinical, radiological and biological data obtained on admission and during the first day were recorded. Data from the 2 patient groups were compared using univariate and multivariate analyses in order to construct a scale. For retrospective observational analysis of medical records, French law does not require specific approval from an internal review board or the consent of patients.

\section{Statistical Analysis}

Results are expressed as median values [25-75\% interquartile range (IQR)] or percentages. The study endpoint was immune cause of DAH, and group 1 was compared to group 2 in subsequent analyses. Marginal association between single variables and an immune cause of DAH was assessed by a Mann-Whitney $\mathrm{U}$ test for quantitative variables and a $\chi^{2}$ or Fisher's exact test for qualitative variables. Multiple logistic regression was used to determine a set of variables independently associated with an immune cause of DAH and to construct a simplified scoring system. Variables associated with an immune cause at a 0.05 significance level were included in the multiple model. Given the moderate sample size of this study, data reduction was applied before performing the multivariate analysis (without considering their association with the outcome) using heuristic shrinkage [18]. At this stage, missing values were imputed to the sample's median value of the variable, and data were transformed into categorical variables. The median was used to define the threshold. A backward stepwise procedure was used for variable selection based on Akaike's information criterion. The validity of the logistic regression model was checked using the le Cessie and van Houwelingen goodness-of-fit test [19].

Internal validation of the model was performed by bootstrapping $[18,20]$. This procedure was based on the random generation of 200 samples from the original data, identical in size, taking into account the balance between immune and non-immune causes of $\mathrm{DAH}$, drawn with replacement. For these samples, the whole variable selection procedure was applied and the performance measures of the derived model were calculated. The discriminative ability of the models was evaluated by the $c$ index [identical to the area under the receiver operating characteristic (ROC) curve] and calibration was evaluated by the calibration slope [21, 22]. The models estimated in each bootstrap sample were then evaluated in the original sample, and the differences between the performance on the bootstrap sample and on the original sample were taken as a measure of the over-optimism of the selected model. The final model performance was then corrected by this over- 
optimism, i.e. the area under the ROC curve (AUC) was reduced accordingly, and regression coefficient estimates were multiplied by the calibration slope. These coefficients were then rounded up to the nearest integer to construct a simplified score. Discriminative performances were illustrated by an ROC curve.

All tests were two-sided at a 0.05 significance level. Analyses were carried out using $\mathrm{R}$ statistical software (The R Foundation for Statistical Computing, Vienna, Austria).

\section{Results}

\section{Population Characteristics}

The characteristics of the 76 patients included in this study are summarized in table 1 . There were 50 men and 26 women with a median age of 52 years (IQR 35-66 years). Fifty-five patients (72\%) were admitted to the ICU and 21 patients $(28 \%)$ to the respiratory care unit. The intra-hospital mortality rate due to refractory DAH was $24 \%$ (22\% in group 1 and 26\% in group 2).

The median duration of respiratory symptoms was 11 days (IQR 4-30 days). The most common presenting symptoms were cough and haemoptysis. Chest X-rays showed an alveolar pattern in $44 \%$, an interstitial pattern in $33 \%$, a mixed pattern in $18 \%$ and a normal pattern in $5 \%$ of cases. Fiberoptic bronchoscopy was performed within a median of 11 days (IQR 4-30 days) after the first respiratory symptom and revealed diffuse bloody secretions in 54\% of patients. Blood was present in BAL in $83 \%$ of patients and the median percentage of siderophages in the remaining $17 \%$ of patients was $75 \%$ (IQR $51-95 \%$ ). In the 4 patients who underwent BAL less than 4 days after the first symptom, siderophage counts were less than $20 \%$.

Most patients exhibited low-grade fever; a temperature $\geq 39^{\circ} \mathrm{C}$ was observed in only $17 \%$ of patients. Renal involvement was the main extrapulmonary symptom. Ear-nose-throat symptoms were nasal discharge or obstruction in most of the cases. Cutaneous lesions were subcutaneous nodules, vascular purpura, rash, haematoma and/or ulcerations.

As shown in figure 1a, the time between admission and the first specific treatment was available for 27 of the 34 patients with DAH of immune cause; the median delay was 2 days (IQR 1-7 days).

\section{Univariate Analysis}

The results of the univariate analysis are presented in table 2. According to univariate analysis, the following features were significantly associated with an immune cause of DAH: duration of respiratory symptoms $\geq 11$ days, presence of constitutional symptoms (defined as in-
Table 1. Patient characteristics on admission

Total $(\mathrm{n}=76)$

Age, years
Sex ratio (M/F)
Previous cardiovascular disease ${ }^{\mathrm{a}}, \mathrm{n}(\%)$
Effective anticoagulant or
antiaggregant treatment $\mathrm{t}^{\mathrm{b}}, \mathrm{n}(\%)$
Smokers, $\mathrm{n}(\%)$
$\quad$ Former
Current

$52(35.5-66.5)$

$50 / 26$

29 (38)

$23(30)$

$20 / 66(30)$

$22 / 66(33)$

Time since the first respiratory symptom, days

Dyspnea, n (\%)

Haemoptysis, n (\%)

$11(4-30)$

$65(86)$

$47(62)$

$89(80-95)$

Percutaneous oxygen saturation in room air

$28(24-33)$

Respiratory rate, cycles per minute

Crackles, n (\%)

$57(75)$

Pulmonary infiltrates on CXR, $\mathrm{n}(\%)$

$72(95)$

BAL analysis

Bloody BAL fluid, \%

Cell count $(\mathrm{n}=48)^{\mathrm{c}}$, cells $/ \mathrm{mm}^{3}$

Macrophages $(n=64)^{c}, \%$

Siderophages, $\%$

Neutrophils $(n=64)^{c}, \%$

Lymphocytes $(\mathrm{n}=64)^{\mathrm{c}}$, \%

Fatigue and/or weight loss ${ }^{\mathrm{d}}, \mathrm{n}(\%)$

Temperature, ${ }^{\circ} \mathrm{C}$

Systolic blood pressure, $\mathrm{mm} \mathrm{Hg}$

Arthralgias and/or arthritis, n (\%)

Myalgias, n (\%)

Neurological symptoms, n (\%)

Gastrointestinal symptoms, n (\%)

83

$285(160-565)$

$67(43-78)$

$73(57-95)$

$18(6-41)$

$6(2-15)$

22 (29)

$37.5(37-38.5)$

$130(120-160)$

15 (20)

$10(13)$

13 (17)

$10(13)$

$26(34)$

25 (33)

Cutaneous lesions, n (\%)

Glomerular filtration rate

(Cockroft formula), $\mathrm{ml} / \mathrm{min}$

Microscopic haematuria $(n=61)^{\mathrm{c}}, \%$

$64(35-100)$

$32 / 61(52)$

$0.3(0-1.7)$

$62(57-68)$

$8.7(7-12)$

Plasma protein level $(\mathrm{n}=60)^{\mathrm{c}}, \mathrm{g} / \mathrm{l}$

$\gamma$-globulin levels $(n=50)^{\mathrm{a}}, \mathrm{g} / \mathrm{l}$

Haemoglobinemia, g/dl

$10.6(8.5-12.9)$

Values in parentheses represent medians (25-75\% IQR) or percentages. CXR $=$ Chest X-ray.

a Previous cardiovascular disease is defined as arterial hypertension, cardiomopathy, valvular heart disease, coronaropathy, stroke or other symptomatic atheromatosis.

${ }^{\mathrm{b}}$ Effective antianticoagulant treatment is defined by biological haemostasis tests, and effective antiaggregant treatment is defined by an intake of antiaggregant (usually acetylsalicylic acid) during the week before DAH.

${ }^{c}$ Numbers in parentheses indicate the number of patients with data available.

${ }^{\mathrm{d}}$ Constitutional symptoms are defined as incapacitating fatigue and/or 5\% weight loss for at least 1 month before admission. 

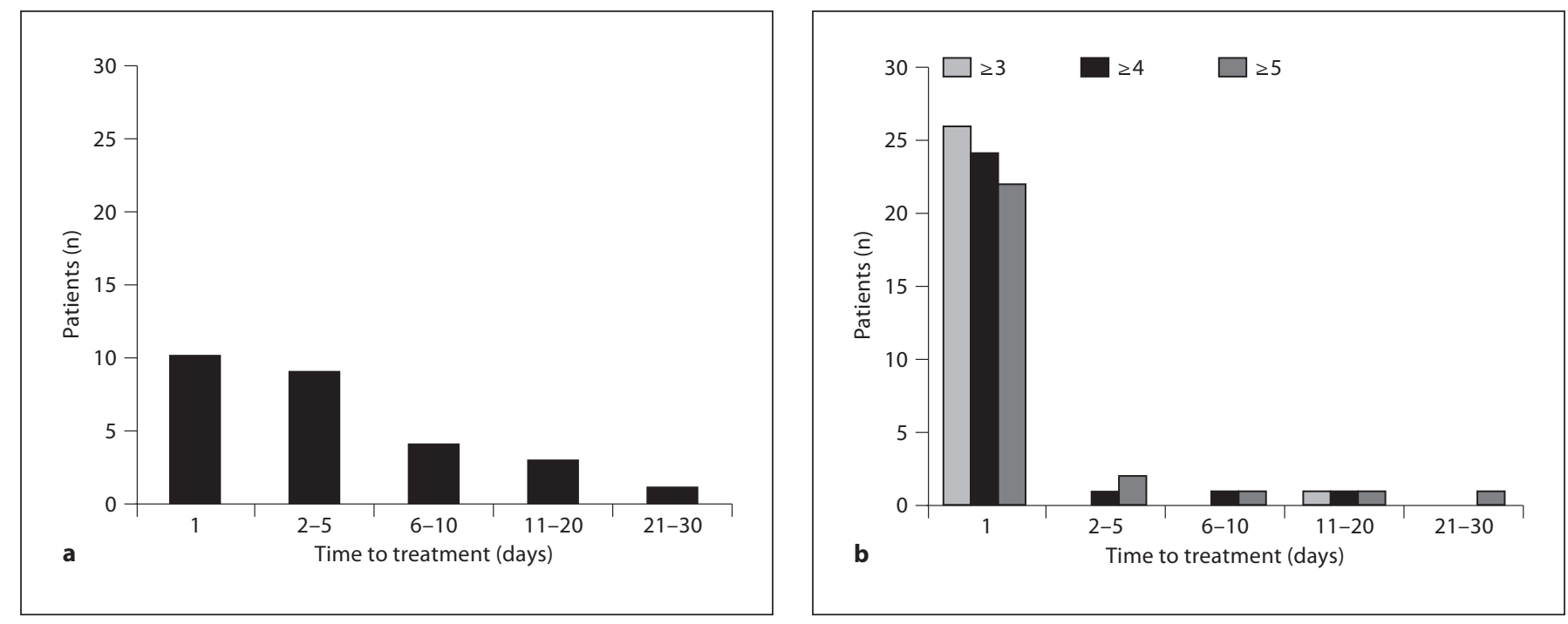

Fig. 1. a Time observed in the study population. b Time expected if the scale were applied to the study population with 3 different thresholds $(\geq 3, \geq 4$ and $\geq 5)$.

Table 2. Statistically different features between group 1 (DAH of immune cause) and group 2 (DAH of non-immune cause) in univariate analysis

\begin{tabular}{|c|c|c|c|}
\hline & $\begin{array}{l}\text { Group 1 } \\
(\mathrm{n}=32)\end{array}$ & $\begin{array}{l}\text { Group } 2 \\
(\mathrm{n}=44)\end{array}$ & $\begin{array}{l}\mathrm{p} \\
\text { value }\end{array}$ \\
\hline Time since the first respiratory symptoms $\geq 11$ days & $26 / 32$ & $16 / 44$ & $10^{-4}$ \\
\hline Systolic blood pressure $>160 \mathrm{~mm} \mathrm{Hg}(\mathrm{n}=64)^{\mathrm{a}}$ & $11 / 26$ & $6 / 38$ & 0.018 \\
\hline Fatigue and/or weight loss ${ }^{\mathrm{b}}$ & $16 / 32$ & $6 / 44$ & $10^{-3}$ \\
\hline Arthralgia and/or arthritis & $14 / 32$ & $1 / 44$ & $3.10^{-5}$ \\
\hline Myalgias & $9 / 32$ & $1 / 44$ & $3.10^{-3}$ \\
\hline Ear-nose-throat symptoms & $15 / 32$ & $11 / 44$ & 0.047 \\
\hline Cutaneous lesions & $17 / 32$ & $8 / 44$ & $10^{-3}$ \\
\hline Haematuria $\geq 10^{4}$ cells $/ \mathrm{ml}(\mathrm{n}=61)^{\mathrm{a}}$ & $26 / 31$ & $6 / 30$ & $2.10^{-6}$ \\
\hline Proteinuria $\geq 1 \mathrm{~g} / \mathrm{l}(\mathrm{n}=67)^{\mathrm{a}}$ & $19 / 30$ & $5 / 37$ & $7.10^{-5}$ \\
\hline Glomerular filtration rate $<80 \mathrm{ml} / \mathrm{min}(\text { Cockroft formula; } \mathrm{n}=65)^{\mathrm{a}}$ & $23 / 27$ & $17 / 38$ & $2.10^{-3}$ \\
\hline Haemoglobinemia $<10 \mathrm{~g} / \mathrm{dl}$ & $22 / 32$ & $12 / 44$ & $3.10^{-4}$ \\
\hline$\gamma$-globulin levels $\geq 9 \mathrm{~g} / \mathrm{l}(\mathrm{n}=50)^{\mathrm{a}}$ & $14 / 22$ & $9 / 28$ & 0.026 \\
\hline
\end{tabular}

Results are expressed as the ratio of the number of patients positive for each feature reported to the number of patients in the related group for which the data was available.

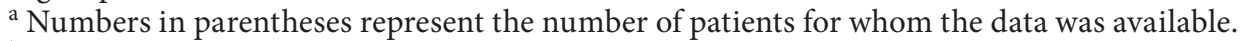

${ }^{\mathrm{b}}$ Constitutional symptoms are defined as incapacitating fatigue and/or 5\% weight loss for at least 1 month before admission.

capacitating fatigue and/or $5 \%$ weight loss for at least 1 month before admission), increased systemic blood pressure, microscopic haematuria, proteinuria, low glomerular filtration rate, arthralgias, myalgias, ear-nose-throat symptoms, cutaneous lesions, low haemoglobinemia and increased $\gamma$-globulin levels. The other features were not statistically different between the 2 groups.

\section{Multivariate Analysis}

Multivariate analysis (table 3) showed that duration of respiratory symptoms prior to hospitalization $(\mathrm{p}=0.017)$, presence of fatigue and/or weight loss $(\mathrm{p}=0.006)$, arthralgia/arthritis $(\mathrm{p}=0.004)$ and proteinuria $\geq 1 \mathrm{~g} / \mathrm{l}(\mathrm{p}=$ 0.0002 ) were significant factors independently associated with an immune cause of DAH. 
The scale for early prediction of an immune cause, defined by using the $\beta$-coefficient of the multivariate model, is shown in table 4 . The ROC curve of the scale is presented in figure 2 . Each of the 4 statistically significant independent variables was attributed a score by the statistical software as follows: 2 points if time since the first respiratory symptom was longer or equal to 11 days, 2 points if fatigue and/or weight loss were present, 3 points if arthralgia or arthritis was present and 3 points if proteinuria was $\geq 1 \mathrm{~g} / \mathrm{l}$. Therefore, the scale ranged from 0 to a maximum of 10 points. The apparent AUC for predicting DAH related to an immune cause was 0.938 . After bootstrap analysis, the bootstrap-corrected AUC was 0.913 .

\section{Discussion}

In this study of 76 consecutive cases of symptomatic $\mathrm{DAH}$ in immunocompetent patients, we were able to identify 4 independent parameters associated with an immune cause of DAH. These variables, which can be easily collected within the first $24 \mathrm{~h}$ after admission, were used to build a diagnostic scale of immune DAH with an AUC of 0.913 after correction by bootstrap analysis.

Published reports of series of patients with symptomatic $\mathrm{DAH}$ are few, and most studies are limited to immune-related DAH due to restrictive inclusion criteria $[1$, $3,5]$. Consistent with previous studies, small-vessel vasculitis and SLE were the 2 most frequent immune causes of DAH in our series $[1,3,5,7,10]$. Among the remaining non-immune causes of DAH, clotting disorders and cardiac failure are the leading causes [23]. Anecdotal evidence of non-immune DAH related to barotraumatism, drug reaction, infection and cancer exists in the literature, but the relative contribution of these causes is unknown [24-28]. Regardless of the cause, DAH is a severe condition with an intra-hospital mortality rate of $24 \%$ in this study. In patients with ANCA (anti-neutrophil cytoplasmic antibodies)-associated microscopic polyangiitis, DAH was associated with a relative risk of death of $9 \%$ and a mortality rate due to DAH of $13 \%$ at 6 months [10, 29]. Mortality rates for SLE vary widely between studies, but may be approximately $50 \%$ [7]. Morbidity is also high. The long-term occurrence of a restrictive syndrome after $\mathrm{DAH}$ has been reported but data are insufficient to allow correlation with the initial severity of DAH [10]. In the case of a pulmonary-renal syndrome, glomerulonephritis could lead to irreversible renal failure, especially when the initial creatinine value is high [29]. Indeed, because of the severity of both DAH and glomerulonephritis, most au-

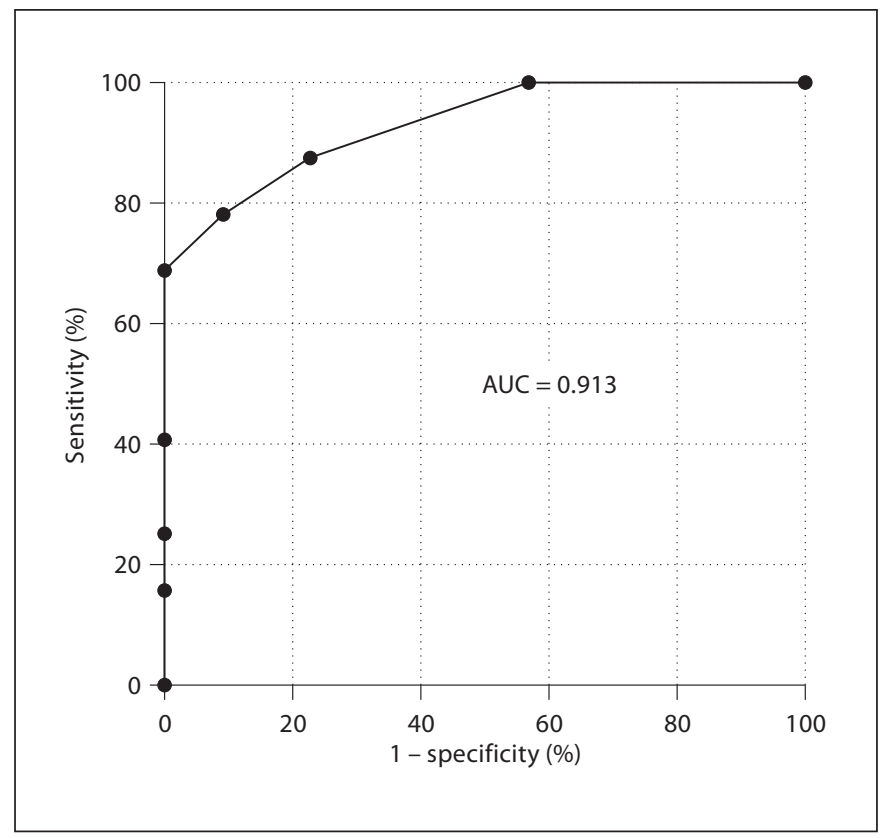

Fig. 2. ROC curve of the clinical scale for the diagnosis of DAH of immune cause in the present population.

Table 3. Multiple logistic regression model with OR for DAH related to an immune cause

OR $\quad 95 \% \mathrm{CI} \quad \mathrm{p}$

Time since the first respiratory symptoms $\geq 11$ days

Fatigue and/or weight loss ${ }^{\mathrm{a}}$

Arthralgia/arthritis

Proteinuria $\geq 1 \mathrm{~g} / \mathrm{l}$
$1.46-48$

$2.5-97.6$

$3.8-968$

$59 \quad 6.8-516$

0.006

0.004

0.0002

a Constitutional symptoms are defined as incapacitating fatigue and/or $5 \%$ weight loss for at least 1 month before admission.

Table 4. The scale defined using $\beta$-coefficients of the multivariate analysis

\begin{tabular}{lc} 
Variable & Points \\
\hline Time since the first respiratory symptoms $\geq 11$ days & +2 \\
Fatigue and/or weight loss ${ }^{\text {a }}$ & +2 \\
Arthralgia/arthritis & +3 \\
Proteinuria $\geq 1 \mathrm{~g} / 1$ & +3 \\
\hline \multicolumn{2}{c}{ a Constitutional symptoms are defined as incapacitating fa- } \\
tigue and/or 5\% weight loss for at least 1 month before admission.
\end{tabular}

Respiration 2010;80:313-320 
thors have emphasized the importance of early diagnosis and treatment with immunosuppressors and plasma exchange, particularly when an immune cause is present $[6$, 29-32]. Unfortunately, this management strategy raises several problems, especially in the acutely ill, and thus 'emergency' treatment is frequently delayed (fig. 1a). Firstly, tests for certain critical markers (e.g. ANCA or antibasement membrane antibody testing) are not routinely available. In large university hospitals (such as ours), results are generally available within the first $24 \mathrm{~h}$ if emergency testing is requested by the admitting clinician. However, results may not be available for several days in some general hospitals (and in most places at weekends) or in hospitals in less industrialized countries. Secondly, obtaining histological samples, especially via renal or lung biopsy, may be difficult and sometimes impossible in critically ill patients admitted to an ICU for acute respiratory failure. Lung biopsy may often be non-diagnostic and risky, and other biopsy procedures (e.g. skin, nasal, etc.) are time-consuming and have a low yield $[5,32]$.

To our knowledge, this study is the first to attempt to detect an immune cause for DAH on the basis of simple routine data obtained on admission. We identified 4 variables associated with immune-mediated DAH after multivariate analysis. The duration of respiratory symptoms before hospital admission is a predictive factor. Previous studies have shown that DAH often occurs as a slow, evolving process in vasculitis $[10,33]$. In contrast, DAH frequently has a sudden onset in SLE [7]. Indeed, in the present study, only 6 patients in group 1 had respiratory symptoms for less than 11 days, but 3 of them had SLE. The presence of other symptoms prior to admission (fatigue and/or weight loss during the month prior to presentation) and arthralgias are other independent predictive factors of an immune cause, consistent with previous reports $[6,34$, 35]. Finally, the multivariate analysis study highlighted the importance of renal involvement (assessed by the presence of proteinuria), as previously mentioned by ter Maaten et al. [34] and Cordier et al. [36]. However, as reported by Niles et al. [32], the presence of renal and pulmonary symptoms is not always synonymous with immune-mediated pulmonary-renal syndrome and is sometimes related to coexisting independent conditions.

The scoring system built using the 4 predictive factors is easy to use, inexpensive and may be performed at the bedside at any time. The scale could add significant information to the routine medical evaluation and alert the physician to the eventuality of an immune cause of DAH, and it could be particularly useful for physicians with little experience in systemic diseases. As shown in figure 1, it could significantly reduce the delay between hospital admission and diagnosis of immune alveolar haemorrhage and thus treatment, which could potentially be life and/or function saving. If a threshold of 4 or more points were used, the scale would be of high specificity for DAH of immune cause (fig. 2). In the present population, the use of this cut-off value would have indicated treatment in 24 of the 27 patients with immune-related DAH on the first day (fig. 1b). On the other hand, only 4 of the 44 patients in the non-immune group had scores of 4 or more. Two of these 4 patients had cardiac failure identified on admission with cardiac ultrasonography and thus did not receive steroids. The 2 remaining patients had idiopathic DAH with bland haemorrhagic and siderophagic alveolitis on transbronchial lung biopsies and finally received steroid treatment. None of the patients with non-immune DAH had a score of 5 or more in the present population. We would not recommend the use of a threshold of 3 as it would have led to steroid treatment of DAH of non-immune cause.

Although DAH is a very rare condition, this study is to our knowledge the largest study in unselected immunocompetent hosts. The validity of diagnosis or prediction criteria should be tested on another study population. As this was not feasible (due to the rarity of symptomatic DAH), we used complex statistical analysis to assess the validity of the results. Internal validation of the scale by bootstrapping and correction for over-optimism allowed confirmation of the validity of the data and provided an evaluation of the potential real-life performance of the scale. However, validation of the scale with other populations is required. Furthermore, whether or not the scale improves the prognosis remains to be demonstrated. Although a crucial role of early steroid and/or immunosuppressor treatment in the prognosis of immune DAH is suggested by some experts, this remains to be proven. Better survival was suggested in a study of 34 patients with DAH due to SLE when treated within $48 \mathrm{~h}$ with large methylprednisolone doses [37]. This may be true in DAH due to other immune causes. One could also make an analogy between DAH and acute glomerulonephritis, in which early treatment is a determinant of renal recovery $[1,29,38,39]$. For example, in a study of 107 patients with ANCA-associated glomerulonephritis, entry serum creatinine was one of the main predictive factors of chronic renal insufficiency [29]. In the same study, the absence of immunosuppressors (especially cyclophosphamide) and the presence of DAH were associated with relative risks of mortality of 5.6 and 8.6, respectively. Considering previous data and the results of the present study, we would recommend being highly suspicious of 
an immune cause of DAH if 2 or more scale criteria are present on admission. Further investigation should be promptly initiated to confirm the immune cause and the use of pulse steroids should be considered, as previously reported [40]. However, some diagnostic testing, especially cardiac ultrasonography, should remain systematic before any treatment decisions are made. Finally, we would not recommend administration of cyclophosphamide, other immunosuppressive drugs [41] or plasmapheresis on the basis of the results of this scale.

\section{Conclusions}

In unselected immunocompetent patients presenting with $\mathrm{DAH}$, a simple scale can be used to differentiate $\mathrm{DAH}$ of immune and non-immune cause in the absence of routine and rapid $(<24 \mathrm{~h})$ immune tests. This scale could help guide diagnostic and treatment decisions and thus may improve prognosis. The scale should now be evaluated in prospective studies.

\section{References}

1 Holdsworth S, Boyce N, Thomson NM, Atkins RC: The clinical spectrum of acute glomerulonephritis and lung haemorrhage (Goodpasture's syndrome). Q J Med 1985;55: $75-86$.

2 Ioachimescu OC, Stoller JK: Diffuse alveolar hemorrhage: diagnosing it and finding the cause. Cleve Clin J Med 2008;75:258, 260, 264-265 passim.

3 Leatherman JW, Davies SF, Hoidal JR: Alveolar hemorrhage syndromes: diffuse microvascular lung hemorrhage in immune and idiopathic disorders. Medicine (Baltimore) 1984;63:343-361.

4 Specks U: Diffuse alveolar hemorrhage syndromes. Curr Opin Rheumatol 2001;13:1217.

5 Travis WD, Colby TV, Lombard C, Carpenter HA: A clinicopathologic study of 34 cases of diffuse pulmonary hemorrhage with lung biopsy confirmation. Am J Surg Pathol 1990; 14:1112-1125

-6 Gallagher H, Kwan JT, Jayne DR: Pulmonary renal syndrome: a 4 year, single-center experience. Am J Kidney Dis 2002;39:42-47.

$\checkmark 7$ Zamora MR, Warner ML, Tuder R, Schwarz MI: Diffuse alveolar hemorrhage and systemic lupus erythematosus: clinical presentation, histology, survival, and outcome. Medicine (Baltimore) 1997;76:192-202.

8 Green RJ, Ruoss SJ, Kraft SA, Duncan SR, Berry GJ, Raffin TA: Pulmonary capillaritis and alveolar hemorrhage: update on diagnosis and management. Chest 1996;110:13051316.

9 Collard HR, Schwarz MI: Diffuse alveolar hemorrhage. Clin Chest Med 2004;25:583592, vii.

$\checkmark 10$ Lauque D, Cadranel J, Lazor R, Pourrat J, Ronco P, Guillevin L, Cordier JF: Microscopic polyangiitis with alveolar hemorrhage: a study of 29 cases and review of the literature. Groupe d'Etudes et de Recherche sur les Maladies 'Orphelines' Pulmonaires (GERM'O'P). Medicine (Baltimore) 2000;79: 222-233.
11 Jennings CA, King TE Jr, Tuder R, Cherniack RM, Schwarz MI: Diffuse alveolar hemorrhage with underlying isolated, pauciimmune pulmonary capillaritis. Am J Respir Crit Care Med 1997;155:1101-1109.

12 Leavitt RY, Fauci AS, Bloch DA, Michel BA, Hunder GG, Arend WP, Calabrese LH, Fries JF, Lie JT, Lightfoot RW Jr, et al: The American College of Rheumatology 1990 criteria for the classification of Wegener's granulomatosis. Arthritis Rheum 1990;33:11011107.

13 Mills JA, Michel BA, Bloch DA, Calabrese LH, Hunder GG, Arend WP, Edworthy SM, Fauci AS, Leavitt RY, Lie JT, et al: The American College of Rheumatology 1990 criteria for the classification of Henoch-Schonlein purpura. Arthritis Rheum 1990;33:11141121.

14 Levy JB, Turner AN, Rees AJ, Pusey CD: Long-term outcome of anti-glomerular basement membrane antibody disease treated with plasma exchange and immunosuppression. Ann Intern Med 2001;134:10331042.

15 Lazor R, Bigay-Game L, Cottin V, Cadrane J, Decaux O, Fellrath JM, Cordier JF: Alveolar hemorrhage in anti-basement membrane antibody disease: a series of 28 cases. Medicine (Baltimore) 2007;86:181-193.

16 Hochberg MC: Updating the American College of Rheumatology revised criteria for the classification of systemic lupus erythematosus. Arthritis Rheum 1997;40:1725.

17 Arnett FC, Edworthy SM, Bloch DA, McShane DJ, Fries JF, Cooper NS, Healey LA, Kaplan SR, Liang MH, Luthra HS, et al: The American Rheumatism Association 1987 revised criteria for the classification of rheumatoid arthritis. Arthritis Rheum 1988;31 315-324.

18 Harrell FE Jr, Lee KL, Mark DB: Multivariable prognostic models: issues in developing models, evaluating assumptions and adequacy, and measuring and reducing errors. Stat Med 1996;15:361-387.
19 le Cessie S, van Houwelingen HC: A goodness of fit test for binary regression models, based on smoothing methods. Biometrics 1991;47:1267-1282.

-20 Steyerberg EW, Eijkemans MJ, Harrell FE Jr, Habbema JD: Prognostic modeling with logistic regression analysis: in search of a sensible strategy in small data sets. Med Decis Making 2001;21:45-56.

21 Harrell FE Jr, Califf RM, Pryor DB, Lee KL, Rosati RA: Evaluating the yield of medical tests. JAMA 1982;247:2543-2546.

22 Miller ME, Hui SL, Tierney WM: Validation techniques for logistic regression models. Stat Med 1991;10:1213-1226.

$\checkmark 23$ Yigla M, Sprecher E, Azzam Z, Guralnik L, Kapeliovich M, Krivoy N: Diffuse alveolar hemorrhage following thrombolytic therapy for acute myocardial infarction. Respiration 2000;67:445-448.

24 Heresi GA, Farver CF, Stoller JK: Interstitial pneumonitis and alveolar hemorrhage complicating use of rituximab: case report and review of the literature. Respiration 2008; 76 : 449-453.

25 Luks AM, Lakshminarayanan S, Hirschmann JV: Leptospirosis presenting as diffuse alveolar hemorrhage: case report and literature review. Chest 2003;123:639-643.

-26 Schwartz DR, Maroo A, Malhotra A, Kesselman H: Negative pressure pulmonary hemorrhage. Chest 1999;115:1194-1197.

27 Schwarz MI, Fontenot AP: Drug-induced diffuse alveolar hemorrhage syndromes and vasculitis. Clin Chest Med 2004;25:133-140.

28 Segal SL, Lenchner GS, Cichelli AV, Promisloff RA, Hofman WI, Baiocchi GA: Angiosarcoma presenting as diffuse alveolar hemorrhage. Chest 1988;94:214-216.

-29 Hogan SL, Nachman PH, Wilkman AS, Jennette JC, Falk RJ: Prognostic markers in patients with antineutrophil cytoplasmic autoantibody-associated microscopic polyangiitis and glomerulonephritis. J Am Soc Nephrol 1996;7:23-32. 
-30 Haworth SJ, Savage CO, Carr D, Hughes JM, Rees AJ: Pulmonary haemorrhage complicating Wegener's granulomatosis and microscopic polyarteritis. Br Med J (Clin Res Ed) 1985;290:1775-1778.

-31 Jayne DR, Gaskin G, Rasmussen N, Abramowicz D, Ferrario F, Guillevin L, Mirapeix E, Savage CO, Sinico RA, Stegeman CA, Westman KW, van der Woude FJ, de Lind van Wijngaarden RA, Pusey CD: Randomized trial of plasma exchange or high-dosage methylprednisolone as adjunctive therapy for severe renal vasculitis. J Am Soc Nephrol 2007; 18:2180-2188.

>32 Niles JL, Bottinger EP, Saurina GR, Kelly KJ, Pan G, Collins AB, McCluskey RT: The syndrome of lung hemorrhage and nephritis is usually an ANCA-associated condition. Arch Intern Med 1996;156:440-445.
33 Saxena R, Bygren P, Arvastson B, Wieslander J: Circulating autoantibodies as serological markers in the differential diagnosis of pulmonary renal syndrome. J Intern Med 1995; 238:143-152.

34 ter Maaten JC, Franssen CF, Gans RO, van Schijndel RJ, Hoorntje SJ: Respiratory failure in ANCA-associated vasculitis. Chest 1996; 110:357-362.

35 Guillevin L, Durand-Gasselin B, Cevallos R, Gayraud M, Lhote F, Callard P, Amouroux J, Casassus P, Jarrousse B: Microscopic polyangiitis: clinical and laboratory findings in eighty-five patients. Arthritis Rheum 1999; 42:421-430.

36 Cordier JF, Valeyre D, Guillevin L, Loire R Brechot JM: Pulmonary Wegener's granulomatosis: a clinical and imaging study of 77 cases. Chest 1990;97:906-912.
37 Barile LA, Jara LJ, Medina-Rodríguez F, García-Figueroa JL, Miranda-Limón JM: Pulmonary hemorrhage in systemic lupus erythematosus. Lupus 1997;6:445-448.

38 Jara LJ, Vera-Lastra O, Calleja MC: Pulmonary-renal vasculitic disorders: differential diagnosis and management. Curr Rheumatol Rep 2003;5:107-115.

-39 Cui Z, Zhao MH, Xin G, Wang HY: Characteristics and prognosis of Chinese patients with anti-glomerular basement membrane disease. Nephron Clin Pract 2005;99:c49-55.

40 Leatherman JW: Immune alveolar hemorrhage. Chest 1987;91:891-897.

41 Pinto LF, Candia L, Garcia P, Marín JI, Pachón I, Espinoza LR, Marquez J: Effective treatment of refractory pulmonary hemorrhage with monoclonal anti-CD20 antibody (rituximab). Respiration 2009;78:106-109. 